\title{
A NEW SPECIES OF WATER MITE FROM THERMAL SPRINGS
}

\author{
By Ruth Marshall,
}

Rockford College, Rockford, Illinois.

During the summer of 1927, Professor Charles T. Brues, of the Bussey Institution for Research in Applied Biology, found several water mites in collections made in thermal springs of Nevada in the course of his investigations upon the life in such habitats. He kindly sent these specimens to the writer for further investigation.

A search in the literature of the Hydracarina reveals very few records of their occurrence in thermal waters. Dr. Karl Viets, of Bremen, who has studied the group extensively, confirms this statement in a private communication to the author. The earliest account appears to be that of Plateau (2) who records the finding of Hydrachna cruenta in springs of a temperature of $46^{\circ} \mathrm{C}$., at Luxeuil, France, in the course of experiments on the determination of the thermal death point of several fresh water arthropods. This record is quoted by Brues (1) in recent papers on life in thermal waters. The identity of this species seems to be in some doubt, but it is probably a widely distributed European form.

Two other records have appeared during the past year. Uchida (4) has described a new species, Eylais thermalis from a single specimen found in a spring of temperature $42^{\circ} \mathrm{C}$., near Taihoku, in the island of Formosa. Dr. Iwan Sokolow (3), examining material collected near Lake Baikal, Siberia, in springs of temperature $45^{\circ} \mathrm{C}$., found three individuals which he has described very fully and named Thermacarus thermobius, a new genus and new species. He has also erected for them a new family, Thermacaridae. The American material is a new species belonging to this genus, to which the name Thermacarus nevadensis has been given. 
Thermacarus nevadensis sp. nov.

\author{
Pl. III, fig. 1-9.
}

The body is obovate, slightly widest in the region of the third pair of legs. Females measure 2.50-3.00 mm.; the males are slightly shorter and slimmer, the smallest, a young adult, being but $1.90 \mathrm{~mm}$. It is thus seen to be smaller than $T$. thermobius. The color of the specimens, preserved in alcohol, was dull olive green with some traces of red. Two individuals showed white irregular branching streaks on the dorsal side. The body is low, somewhat arched; dorsally and ventrally the integument is heavily chitinized to form two shields, the dorsal somewhat the smaller, united by a thinner layer. Heavy ridges on the dorsal side enclose two irregularly oval areas, one inside of the other (fig. 1). The double eyes of either side are outside of these ridges. The median sense organ is just within the larger area and is inconspicuous. The heavy integument shows in alcoholic medium a transparent, somewhat irregular layer, below which are low elevations irregularly scattered about on a basal layer; the latter shows rounded pores in groups of some ten to twenty enclosed in an irregularly polygonal meshwork (fig. 7).

The conspicuous feature of the ventral side is the great development of the plates (figs. 2, 8, 9), the epimera closely resembling those of the related species. The first pair of plates, the largest, are fused not only ventrally but also dorsally so as to form a shallow cavity, reaching to the body margin or slightly projecting beyond it in the male, which encloses the small capitulum and the palpi. The fused epimera bear many hairs. The three remaining epimeral pairs are somewhat triangular, except that the fourth in the male is rectangular. Posterior to the epimera in the new species is another plate, a large median one, heavily chitinized and bearing the so-called anal spot, differing in size and shape in the two sexes and in contour in individuals of differing ages, and completing the closure of the genital areas.

The genital area in the male (fig. 2) is nearly circular, past the center of the body and enclosed by the fourth epimera and the medial posterior plate. Its valves are heavily chitinized 
and support several long fine hairs. The female genital area is oval (fig. 8), situated a little above the center of the body and enclosed by the inner ends of the epimera as well as by the posterior plate. The valves of the opening are also heavily chitinized and bear hairs; they show more conspicuously than in the male a division into an anterior inner part and a posterior outer part, the latter showing numerous circular acetabula. One female (fig. 9), was found with the large ovipositor extended through the genital slit. This organ is a delicate, light colored structure within which could be seen the outlines of the nearly circular eggs.

The palpi (fig. $4,5,8$ ) are very small and appeared always within the enclosure formed by the united first pair of epimera. They are flattened and are borne on the sides of a slender capitulum near the top. A conspicuous feature is the presence of two long curved doubly bifid bristles on the distal end of the second segment.

The legs are short, stout, increasing in length from first to fourth. The first three pairs are much like those of the related species and show the same partial union of the first two segments. They bear many heavy bristles, but these are somewhat longer than in the Asiatic form. All end in large double claws, orange red and beset with teeth on the curved side. The fourth leg in the female (fig. 6) is similar to the third but longer; in the male it is considerably modified (fig. 3) and doubtless used as a copulatory organ. The last three segments here are flattened, the fourth showing a plate-like expansion on the inner side; the last two segments are thickly beset with stiff hairs, the fifth being the longest and the sixth not much shorter, but broader with the claws lacking the teeth.

The types were secured in two collections from Nevada, a total of nine individuals.

Three males and four females were found in water of temperature of $43^{\circ} \mathrm{C}$., fifteen miles north of Deeth; and a young male and a female in temperature $42.5^{\circ}-45^{\circ} \mathrm{C}$., in the Valley Hot Springs at Minden.

The new species is seen to be closely related to the Asiatic 
species but differs from it in several well marked characteristics. Specific characters of greatest importance in T. nevadensis appear to be the development of the heavy plate posterior to the epimera, the characters of the palpi with the large curved bifid bristles on the second segment; and the character of the fourth leg of the male with its last three segments elongated as well as flattened and richly supplied with stiff hairs.

\section{Literature Cited.}

1. Brues, C.T. 1924. Observations on Animal Life in the Thermal Waters of Yellowstone Park, with Consideration of the Thermal Environment. Proc. American Acad. Arts and Sci., vol. 59, pt. 15:371-437.

2. Plateau, $F$. 1870. Recherches physico-chimiques sur les Articulés aquatiques. Pt. 1, Mém. Acad. Roy. Sci. Belgique, vol. 36, 68 pp.

3. Sokolow, I. 1927. Thermacarus thermobius, n. g., m. sp., eine Hydracarine aus heisser Quelle. Zool. Anz., LXXIII: 11-20.

4. Uchida, Tohru.1927. Notes on a new Water Mite from a Hot Spring. An. Zool. Japonenses, Vol. 11, 2: 111-114. 
Explanation of Prate III

Fig. 1, dorsal view, male

Fig. 2, ventral plates, male

Fig. 3, fourth leg of male

Fig. 4, palpus, right, inner side (first segment lacking)

Fig. 5, capitulum and palpus

Fig. 6, end of fourth leg, female

Fig. 7, detail of integument

Fig. 8, ventral plates, female

Fig. 9, ovipositor extended 


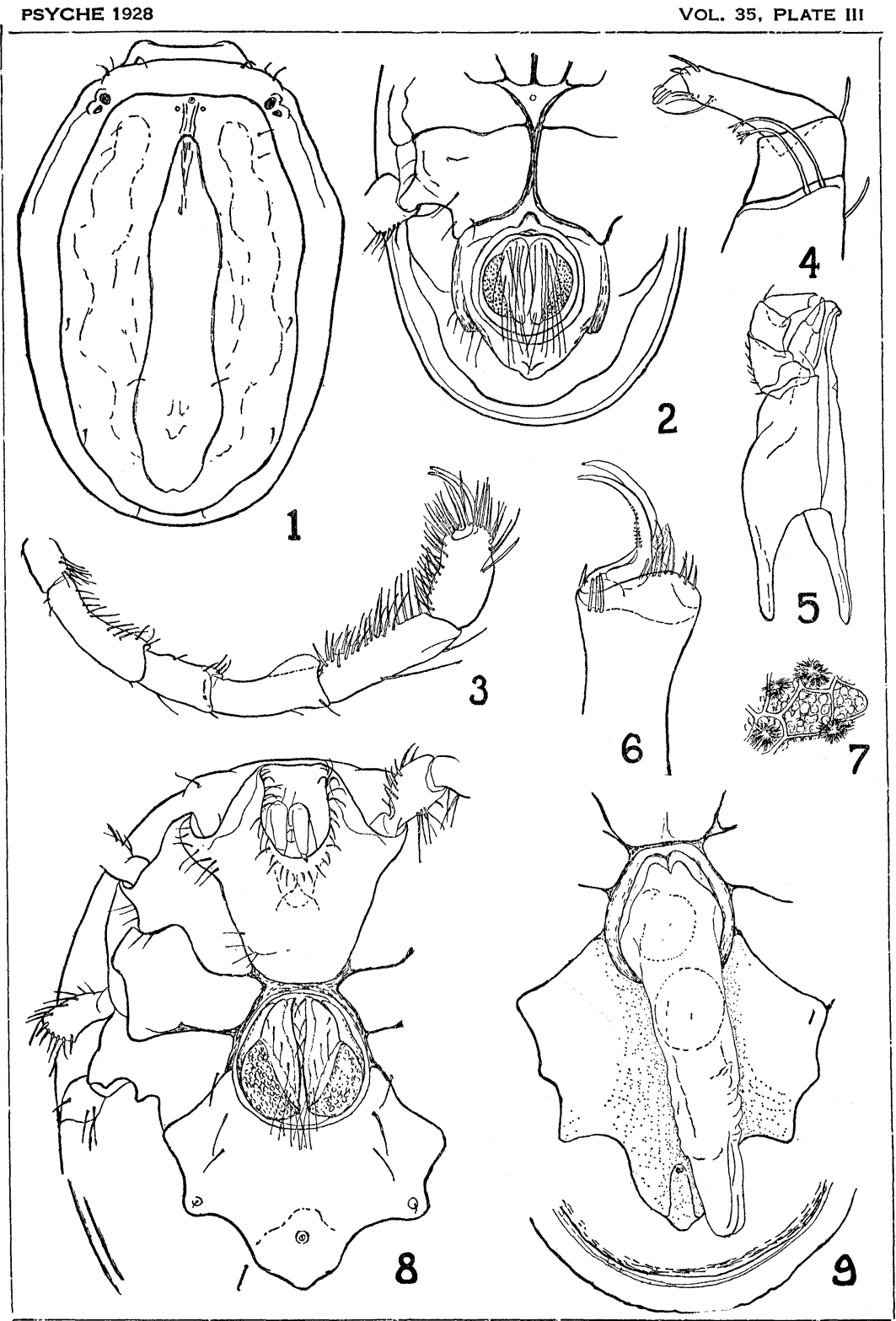

MARSHALL-THERMACARUS 

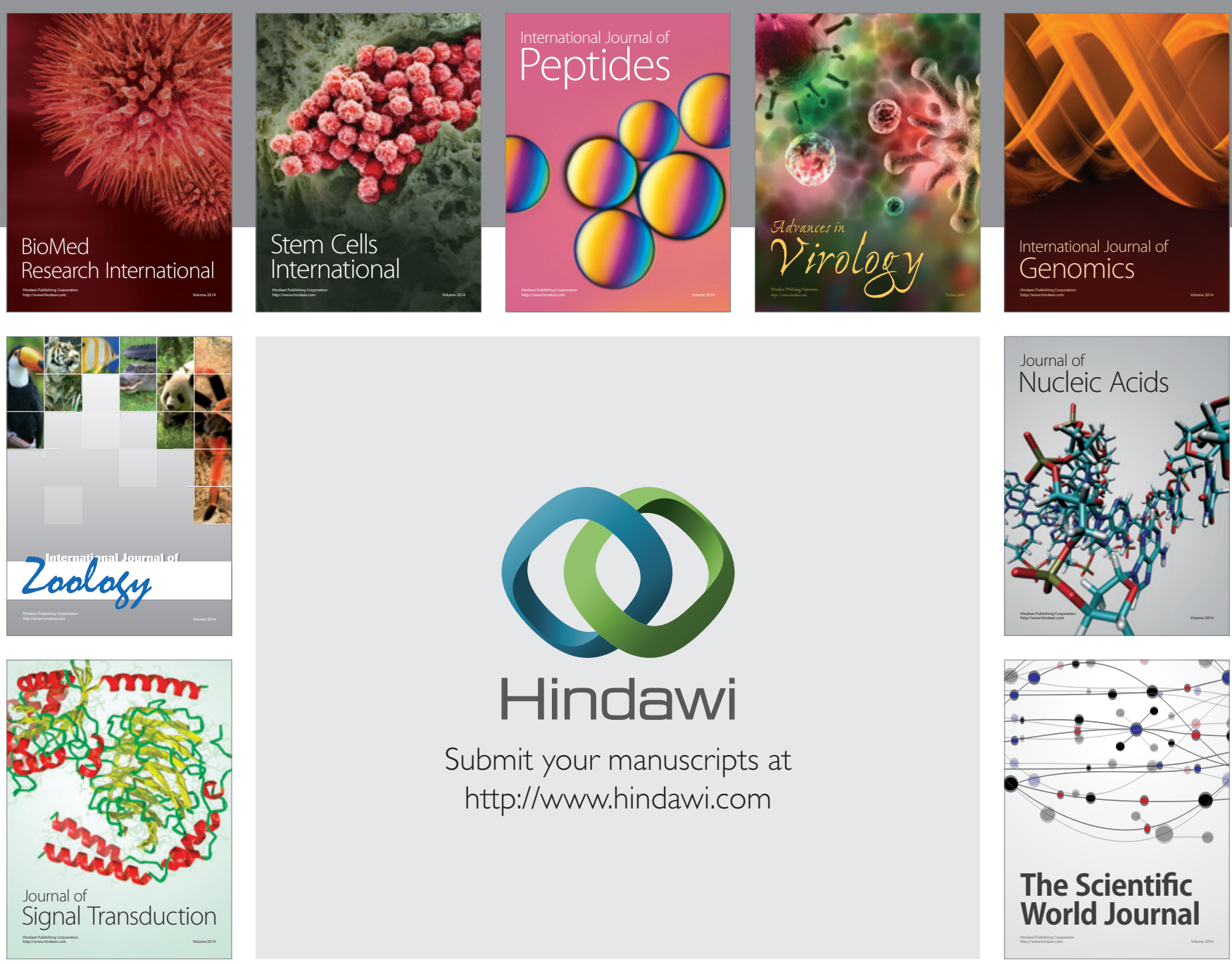

Submit your manuscripts at

http://www.hindawi.com
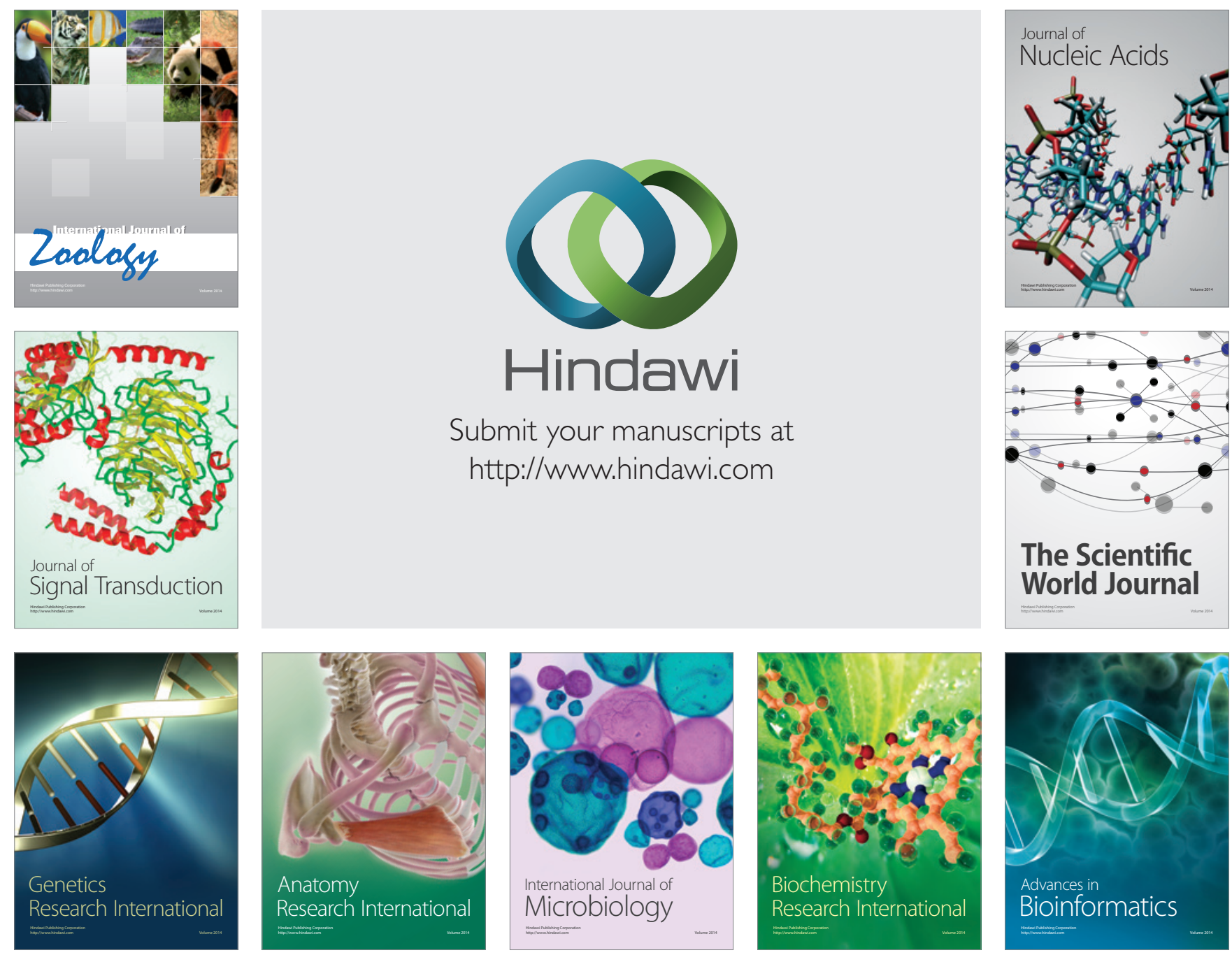

The Scientific World Journal
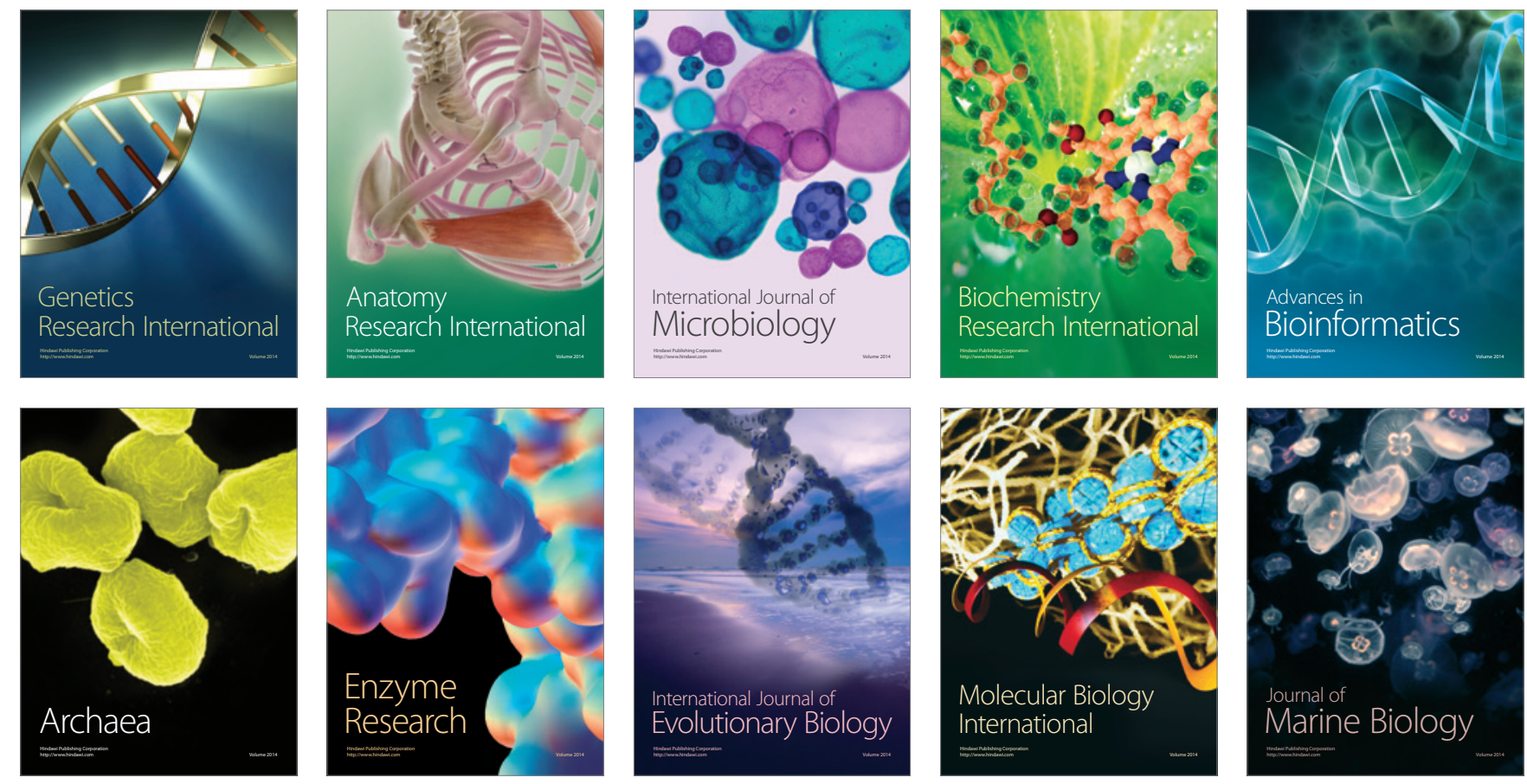